\title{
Get Involved: Nitin Chopra, TMS Young Leader
}

Kelly Zappas

"Get Involved" is a recurring End Notes feature that spotlights the work of TMS volunteers and shows the wide range of activities available through TMS. This month features Nitin Chopra, assistant professor in the Metallurgical and Materials Engineering Department at the University of Alabama. Chopra is an active member of the TMS Young Leaders Program, which helps professionals under the age of 35 to take leadership roles in the society.

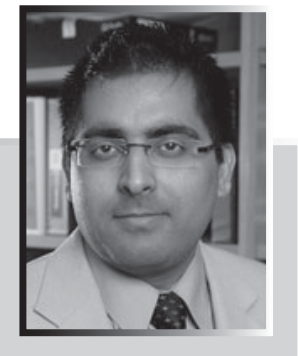

Q. How did you become involved with the Young Leader Program at TMS?

A. The first time I got involved with the Young Leader program was at the TMS 2009 Annual Meeting. I learned about several interesting aspects of this program, such as professional development opportunities, getting involved in Young Leader events, attending luncheons (where I got several opportunities to interact with young TMS members), and, most interestingly, the Young Leader luncheon lecture by one of the senior members of the society. Apart from this, Young Leader committee meetings were very informative about the inner workings of TMS committees, and this was the first committee meeting I attended at TMS. Finally, significant opportunities to collaborate with members who have similar research interests can lead to long-term outcomes of being part of this group. There is lot of energy in this group and one can witness that while attending meetings and luncheons.

Q. As a member of the TMS Young Leaders Committee, what types of volunteer work have you done?

A. I got several opportunities to volunteer for TMS in a number of ways. I was able to get involved in other TMS committees, organized symposia, encouraged younger members of the society to volunteer, and judged for poster competitions and the Materials Bowl.

In addition, I also got an opportunity to collaborate with young leader members to initiate, as well as lead, a new symposium titled Surfaces and Heterostructures at Nano- or Micro-Scale and Their Characterization, Properties, and Applications. This new symposium had a fruitful show at the TMS 2011 Annual Meeting and is expected to grow stronger in the coming years. With this new symposium, my aim is to bring new members to TMS, provide an opportunity to upcoming Young Leaders to participate as session chairs and coorganizers, and open a new platform for discussions and result sharing in an emerging area of nanoscale heterostructures, where my research interests are embedded. In addition, the aim of this symposium is to encourage graduate students and undergraduates to present their work to a diverse audience. For many of them, this may be the first opportunity for presentation.

Q. Is the Young Leaders Committee looking for new members?

A. Yes, the Young Leader Committee is always looking forward to expanding by volunteer activities as well as new members. If you are looking for networking, professional development, and scientific visibility, then this is your place.

Q. Why do you volunteer with TMS?

A. Volunteering with TMS has given me greater professional and scientific exposure that is very necessary for any young or emerging professional's career. I have been the recipient of the 2010 EMPMD Young Leader Professional Development Award, as well as the 2011 Young Leader International Scholar Award. These honors have significantly contributed to my professional development and allowed me to boost my enthusiasm for more innovative services to TMS. This has also led to research collaborations and networking with other scientists and engineers, not only nationwide but internationally.

Q. Is it difficult to balance your work and volunteer activities?

A. As a young assistant professor, it is my ambition to always meet the challenges of balanced research, teaching, and services. This balance allows me to integrate all three activities together to achieve a common goal of good academic citizenship. Being part of several committees, I do attend on-site committee meetings and I also attend teleconference meetings once a month. I don't think this is a heavy load because this is something that benefits me. It helps me to meet new members and network with them for research, understand the inner workings of TMS, and develop communication, as well as leadership skills.

The bottom line is that if I can connect my volunteer activities with my work and especially my research, then it's as enjoyable as my work. For example, the new symposium on Surfaces and Heterostructures at Nano- or MicroScale and Their Characterization, Properties, and Applications, has helped me to highlight the emerging area of nanoscale heterostructures, in which my current research interests lie.

Kelly Zappas is a contributing writer for TMS. 